\title{
Anomalous Temperature Dependence of the Heat of Hydration of Natrolite
}

\author{
Jie Wang and Philip S. Neuhoff*
}

Department of Geological Sciences, University of Florida, 241 Williamson Hall, Gainesville, FL 32611-2120, USA

\begin{abstract}
The temperature dependence of the heat of hydration of natrolite was studied by isothermal adsorption calorimetry from 412 to $472 \mathrm{~K}$. The heat capacity of hydration implied by these results is about 5 times greater than the calorimetric heat capacity of reaction, suggesting atypical behavior across this solid solution.
\end{abstract}

Key Words: Natrolite, hydration, differential scanning calorimetry, enthalpy.

\section{INTRODUCTION}

Natrolite is a natural zeolite with an essentially stoichiometric composition $\left(\mathrm{Na}_{2} \mathrm{Al}_{2} \mathrm{Si}_{3} \mathrm{O}_{10} \cdot 2 \mathrm{H}_{2} \mathrm{O}\right.$; [1]). Its crystal structure is well-known, including positions of $\mathrm{H}_{2} \mathrm{O}$ molecules (in fact, it was the first zeolite structure refined; [1-5]). The framework of natrolite is composed of $\mathrm{Si}$ - and $\mathrm{Al}$ centered tetrahedra. The arrangement of $\mathrm{Si}$ and $\mathrm{Al}$ in the tetrahedral sites is variable but tends to be largely ordered [6, 7]. Channels within the structure contain two $\mathrm{Na}^{+}$ions and two $\mathrm{H}_{2} \mathrm{O}$ molecules per ten framework oxygens oriented in zigzag chains with each $\mathrm{Na}^{+}$coordinated to four framework oxygens and two $\mathrm{H}_{2} \mathrm{O}$ molecules $[3,8,9]$.

The importance of natrolite as a rock-forming mineral [e.g., 1, 7] and its regular compositional and structural properties have led many workers to use this mineral as a reference for studying zeolite dehydration reactions [9-13]. However, unlike most zeolite dehydration reactions that proceed in a continuous fashion with increasing temperature, implying complete solution between the hydrated forms [e.g. 1, 13-16], the dehydration of natrolite occurs abruptly as a function of temperature, as indicated by both isothermal, equilibrium measurements [10] and scanning heating thermogravimentric analysis (TGA; Fig. 1) [see also 1, 13] indicate that dehydration of natrolite occurs abruptly as a function of temperature. This can be seen in the TGA curve of Fig. (1), where it can be seen that the mass of natrolite initially decreases gradually with temperature between 400 and $550 \mathrm{~K}$ and then decreases dramatically at $\sim 575 \mathrm{~K}$. In contrast to the sharp "right angle" topology of the TGA curve of Fig. (1) at $600 \mathrm{~K}$, most zeolites exhibit a more gradual, curved topology in TGA signals as complete dehydration is reached. In addition, a pronounced hysteresis is observed in TGA studies of dehydration/rehydration of natrolite under constant water vapor pressure $\left(P_{\mathrm{H}_{2} \mathrm{O}}\right)$ with rehydration occurring at significantly lower temperatures [13] in contrast to the behavior of many zeolites. The cause(s) of these phenomena are not known, in part because little data are avail-

*Address correspondence to this author at the Department of Geological Sciences, 241 Williamson Hall, P.O. Box 112120, Gainesville, FL 326112120, USA; Tel: 1-352-846-2413; Fax: 1-352-392-9294;

E-mail: neuhoff@ufl.edu able for evaluating the thermodynamic properties of natrolite dehydration.

The present study investigates the thermodynamic behavior of the natrolite- $\mathrm{H}_{2} \mathrm{O}$ system through isothermal adsorption heat measurements as a function of temperature. Reaction behavior exhibited in these experiments indicates that a solvus exists between natrolite and dehydrated natrolite. For the first time, the temperature dependence of the heat of hydration has been directly determined and compared to that calculated from the heat capacities of hydrated and dehydrated natrolite and water vapor. These results demonstrate excess heat capacity across the natrolite-dehydrated natrolite solid solution. Combined, the observations of this study provide evidence for a solvus in the natrolite-dehydrated natrolite solid solution that explains many of the anomalous thermal analysis behaviors exhibited by this mineral.

\section{MATERIALS AND METHODOLOGY}

The sample of natrolite was previously described and characterized by Neuhoff et al. [7; sample NAT001]. It was collected as veins within a metabasaltic tectonic inclusion at the famous Dallas Gem Mine benitoite and neptunite locality, San Benito County, California. Phase pure separates were hand picked, ground in an agate mortar, and sieved to a $20-40 \mu \mathrm{m}$ size fraction. Sample identification and purity were confirmed by X-ray powder diffraction. The composition was determined by electron probe microanalysis at Stanford University to be essentially stoichiometric $\left(\mathrm{Na}_{2} \mathrm{Al}_{2} \mathrm{Si}_{3}\right.$ $\mathrm{O}_{10} \cdot n \mathrm{H}_{2} \mathrm{O}$ ). Water content of the sample was determined in this study by thermogravimetric heating to $1023 \mathrm{~K}$ after the equilibration with a room temperature atmosphere of $50 \%$ relative humidity. The mass loss is about $9.49 \%$ of total sample mass, very close to the ideal water content of natrolite $(9.48 \%)$, and the water content taken to be 2 moles of water per formula unit.

All the experiments in this study were conducted on the Netzsch STA 449C Jupiter simultaneous thermal analysis system at the University of Florida. The core component of the system is a vacuum-tight liquid nitrogen cooled furnace enclosing a sample carrier with an electrode for measurement of temperature differences between the sample and a 


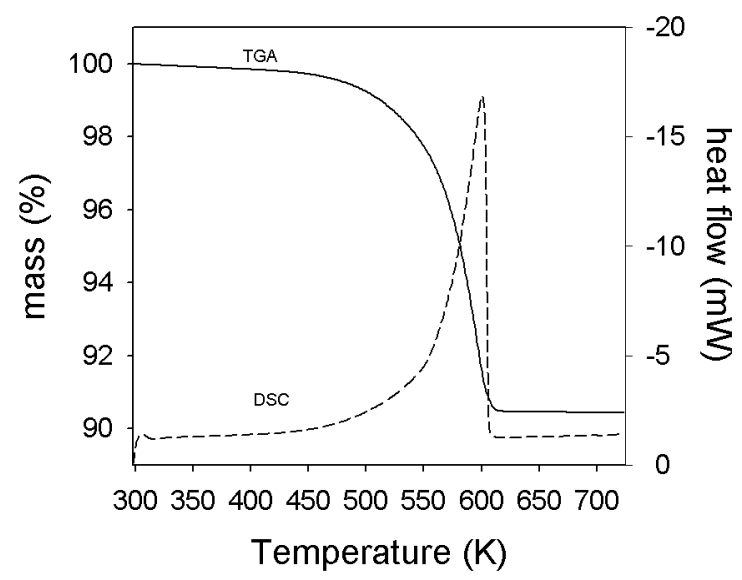

Fig. (1). Scanning-heating (2K/min) TGA (solid) and differential scanning calorimetric (DSC; dashed) behavior of natrolite . Note the abrupt mass loss between 550 and $600 \mathrm{~K}$ accompanied by sharp peak in the DSC signal.

reference pan, generating a heat flux differential scanning calorimetric (DSC) signal. With respect to the present study, an essential aspect of this setup is that the DSC signal is measured simultaneously with TGA signals from a microbalance connected to the sample carrier. This allows the DSC signal to be interpreted directly in terms of water loss or gain to the sample as measured by TGA. All experiments were performed under ultrapure dry or humidified $\mathrm{N}_{2}$ gas.

Temperature and caloric calibrations were performed using data based on the DSC response of standard materials. A multipoint temperature calibration curve was developed using the melting points of $\mathrm{H}_{2} \mathrm{O}, \mathrm{Ga}, \mathrm{In}, \mathrm{Sn}, \mathrm{Bi}, \mathrm{Zn}$ and $\mathrm{Al}$ along with the solid-solid transition points of $\mathrm{CsCl}$ and quartz [17-20]. Because many of these materials are incompatible with the Pt-Rh crucible used in the experiments, temperature calibration was conducted in identical crucibles lined with a sub-mm thick insert of alumina. Caloric calibration was accomplished by the heat-flow rate method [18] using the DSC response of synthetic sapphire [18-22]. The background-corrected DSC response of a synthetic sapphire disc similar in mass to the experimental charges was measured at heating rates of $5,10,15$ and $20 \mathrm{~K} / \mathrm{min}$ over the range of temperatures encountered in this study. Caloric calibration factors calculated from results at each heating rate agreed within $1 \%$ and were a nearly linear function of temperature.

The hydration behavior and heats of hydration of natrolite were assessed under isothermal conditions through isothermal DSC measurements [23]. In each experiment, 20 to $30 \mathrm{mg}$ of hydrated natrolite was placed into an unsealed Pt$\mathrm{Rh}$ crucible with perforated lid and dehydrated by scanning heating from 298 to $733 \mathrm{~K}$ at the rate of $15 \mathrm{~K} / \mathrm{min}$. Care was taken to avoid heating the sample to temperatures under which dehydrated natrolite ("metanatrolite") transforms irreversibly to the form known as $\beta$-metanatrolite $[11,24]$. The sample was then allowed to cool to the experimental temperature under dry $\mathrm{N}_{2}$ gas. After equilibration (20-40 min) under dry gas at this temperature until both DSC and TGA baselines stabilized, the gas stream was changed to humid $\mathrm{N}_{2}$ which was generated by bubbling $\mathrm{N}_{2}$ through saturated $\mathrm{NaCl}$ solution (resulting in an experimental $P_{H_{2} O}$ of $\sim 12 \mathrm{mbar}$; $P_{\mathrm{H}_{2} \mathrm{O}}$ was monitored continuously on the gas stream exiting the system using a flow-through humidity meter manufactured by Sable Systems). The sample was allowed to react until the DSC and TGA baselines stabilized again, indicating a cessation of reaction. Repeated experiments on the same sample indicated a progressive loss of hydration capacity coupled with progressively less energetic heats of reaction. Consequently, a fresh aliquot of sample was used for each experiment.

\section{ISOTHERMAL HYDRATION BEHAVIOR OF NA- TROLITE}

Figs. (2 and 3) illustrate the results of isothermal hydration experiments on natrolite at 382 and $482 \mathrm{~K}$, respectively. The shaded areas of the figures represent isothermal equilibrium of anhydrous natrolite under a flow of dry $\mathrm{N}_{2}$ gas, which was followed by introduction of humidified $\mathrm{N}_{2}$ resulting in uptake of $\mathrm{H}_{2} \mathrm{O}$ by natrolite shortly after the gas composition changed. The hydration of natrolite in both experiments is manifested by the abrupt increase in sample mass accompanied by an endothermic deflection in the DSC signal. The rate of rehydration, given by the first derivative of the TGA signal (DTG) is similar in form to the DSC signal, suggesting little overall change in the average enthalpy of reaction over the course of hydration.

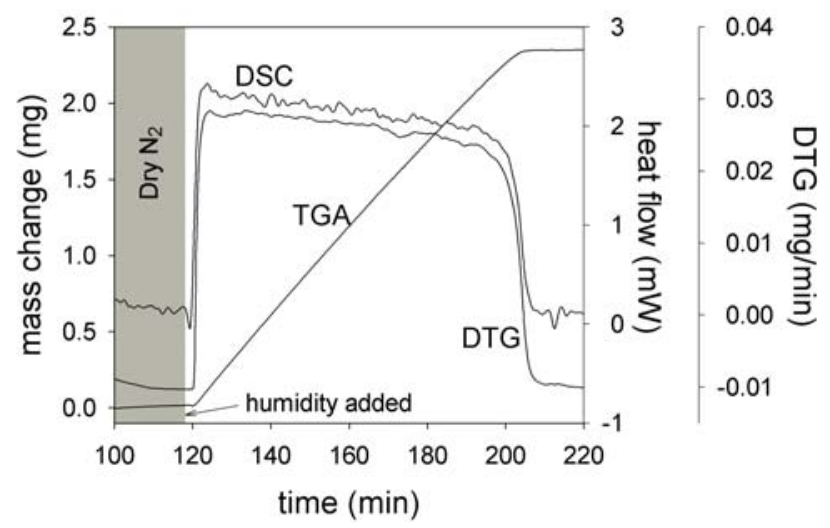

Fig. (2). Example immersion experiment on natrolite conducted at $382 \mathrm{~K}$. Region of the figure encompassed by the gray box denotes initial equilibration of sample at experimental temperature under dry $\mathrm{N}_{2}$. The rest of the experiment was conducted in the presence of a flow of humidified $\mathrm{N}_{2}$.

Close inspection of the TGA data in Figs. ( 2 and 3 ) indicates that the rate of hydration differs between the beginning, middle (majority) and end of the reaction. Initial reaction involves a rapid increase in the rate of hydration (denoted by the positive deflection in the DTG signal). After this initial stage, the rate of hydration is relatively constant for the majority of reaction (near-zero order) until the final portion of the reaction, where the rate of reaction decreases exponentially. The duration of these stages varies with temperature. It can be seen in Fig. (2) that essentially the whole course of reaction at $382 \mathrm{~K}$ is characterized by near-zero order rate behavior (except for rapid increases and decreases in reac- 
tion rate at the induction and cessation of reaction, respectively). At $482 \mathrm{~K}$ (Fig. 3) the zero order portion of the reaction only lasts through about half of the reaction, being followed by a segment where the reaction rate decreases exponentially until reaction stops. It is shown below that these reaction behaviors change progressively between these temperatures.

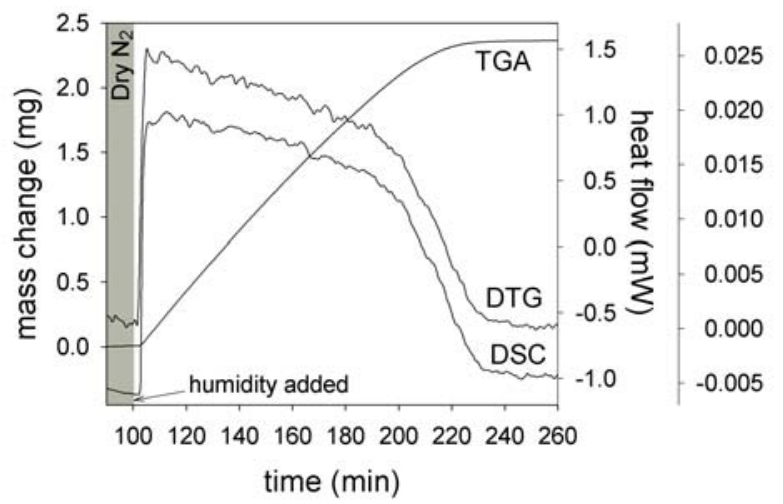

Fig. (3). Example immersion experiment on natrolite conducted at 482 K. See caption to Fig. 2 for explanation.

The dependence of reaction rate on degree of reaction in natrolite is markedly different from that found in other zeolite hydration and dehydration reactions which typically exhibit an exponential decrease in rate as the reaction progresses [14, 23, 25]. This behavior is only apparent in the last half of the experiment shown in Fig. (3). The abrupt increases in rate at the beginning and decreases in rate at the end of the experiments shown in Figs. ( 2 and $\mathbf{3}$ ) are probably artifacts of the induction and cessation of reaction, respectively. The curious aspect of these experiments is the nearzero order reaction kinetics that dominates reaction behavior at $382 \mathrm{~K}$ and occurs over about the first half of the reaction at $482 \mathrm{~K}$. This behavior has been noted previously [23, 26] both during hydration and dehydration reactions in natrolite although its temperature dependence has not been previously studied in detail.

Fig. (4) shows the rate behavior of rehydration in natrolite at several different temperatures as a function of the degree of rehydration (cast in terms of the mole fraction of hydrated natrolite, $X_{\text {hydrated }}$ natrolite). In all cases, the DSC signals (not shown) were topologically similar to the DTG signals as in Figs. (2 and 3). Comparison of the results in Fig. (4) indicates several trends with increasing temperature. First, the degree of hydration obtained under the experimental conditions $\left(\sim 13\right.$ mbar $P_{\mathrm{H}_{2} \mathrm{O}}$ ) decreases progressively with increasing temperature reflecting the tendency of the mineral to progressively dehydrate with increasing temperature. Second, the apparent rate of hydration decreases with increasing temperature (as indicted by the decreasing DTG values with increased temperature for a given value of $X_{\text {hydrated natrolite }}$ ). This effect appears counter to the typical increase in reaction rates with increasing temperature. The cause of this phenomenon is unclear, but may be related to the lower degree of hydration possible with increasing temperature (and thus lowering the thermodynamic driving force). The third phenomenon apparent in Fig. (4) is that the compositional extent of the zero-order kinetic behavior decreases with increasing temperature. At $412 \mathrm{~K}$, this behavior is observed over essentially the whole range of natrolite composition, whereas it is present only up to $\mathrm{X}_{\text {hydrated natrolite }}=\sim 0.6$ at 472 . K. The potential causes of this phenomenon are discussed below.

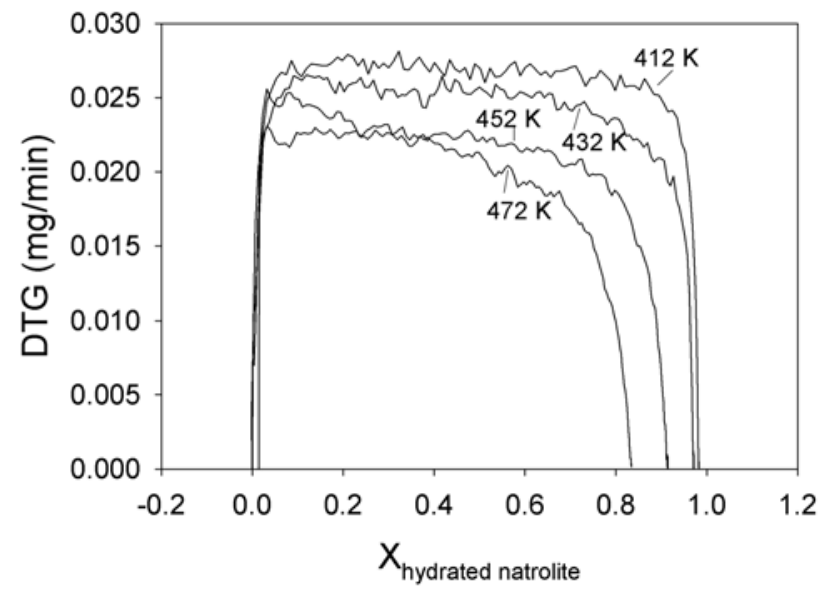

Fig. (4). Comparison between the rate of hydration in natrolite as a function of temperature and degree of hydration.

\section{TEMPERATURE DEPENDENCE OF THE HYDRA- TION HEAT OF NATROLITE}

The heat flow during hydration of natrolite is proportional to the area under the DSC curve, which allows a calculation of the enthalpy of hydration $\left(\Delta \mathrm{H}_{\text {hyd }}\right)$ by the equation:

$\Delta \mathrm{H}_{\text {hyd }}=-18.015 A / k \mathrm{~m}_{\text {gain }}$

where $A$ is the area under the DSC curve, $m_{\text {gain }}$ is the mass gain in the rehydration and $k$ is the caloric calibration factor. The results of $\Delta \mathrm{H}_{\text {hyd }}$ for natrolite at four temperatures for which multiple experiments were conducted are listed in Table 1 and shown in Fig. (5) (the experiments shown above at $382 \mathrm{~K}$ and $482 \mathrm{~K}$ were of insufficient quality to derive useful heat values). The values of $\Delta \mathrm{H}_{\text {hyd }}$ at the same temperature are very close $(<0.5 \%$ difference $)$, and the reported

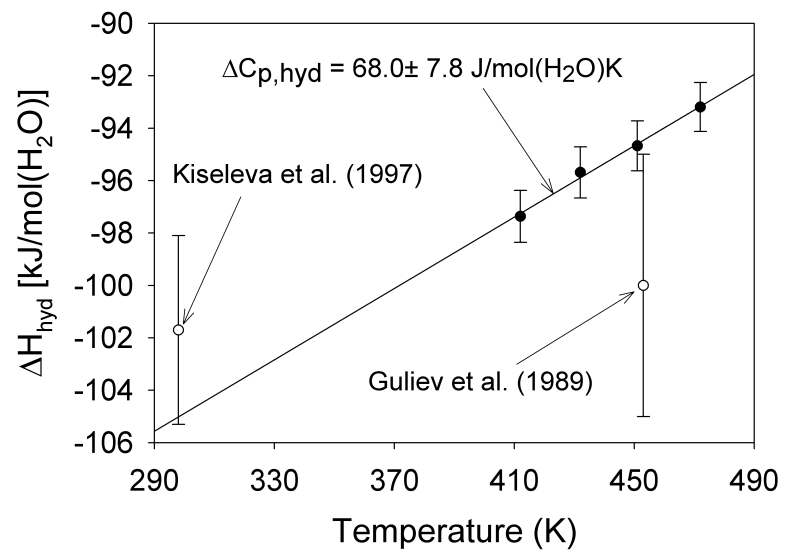

Fig. (5). Enthalpy of hydration of natrolite as a function of temperature. Solid symbols show data generated in this study, open symbols refer to previously reported values [24, 25]. Linear regression of data generated in this study is shown by solid line; slope of this regression corresponds to $\Delta \mathrm{C}_{\mathrm{p} \text {,hyd }}$. 
Table 1. Isothermal Immersion Calorimetric Data for Natrolite

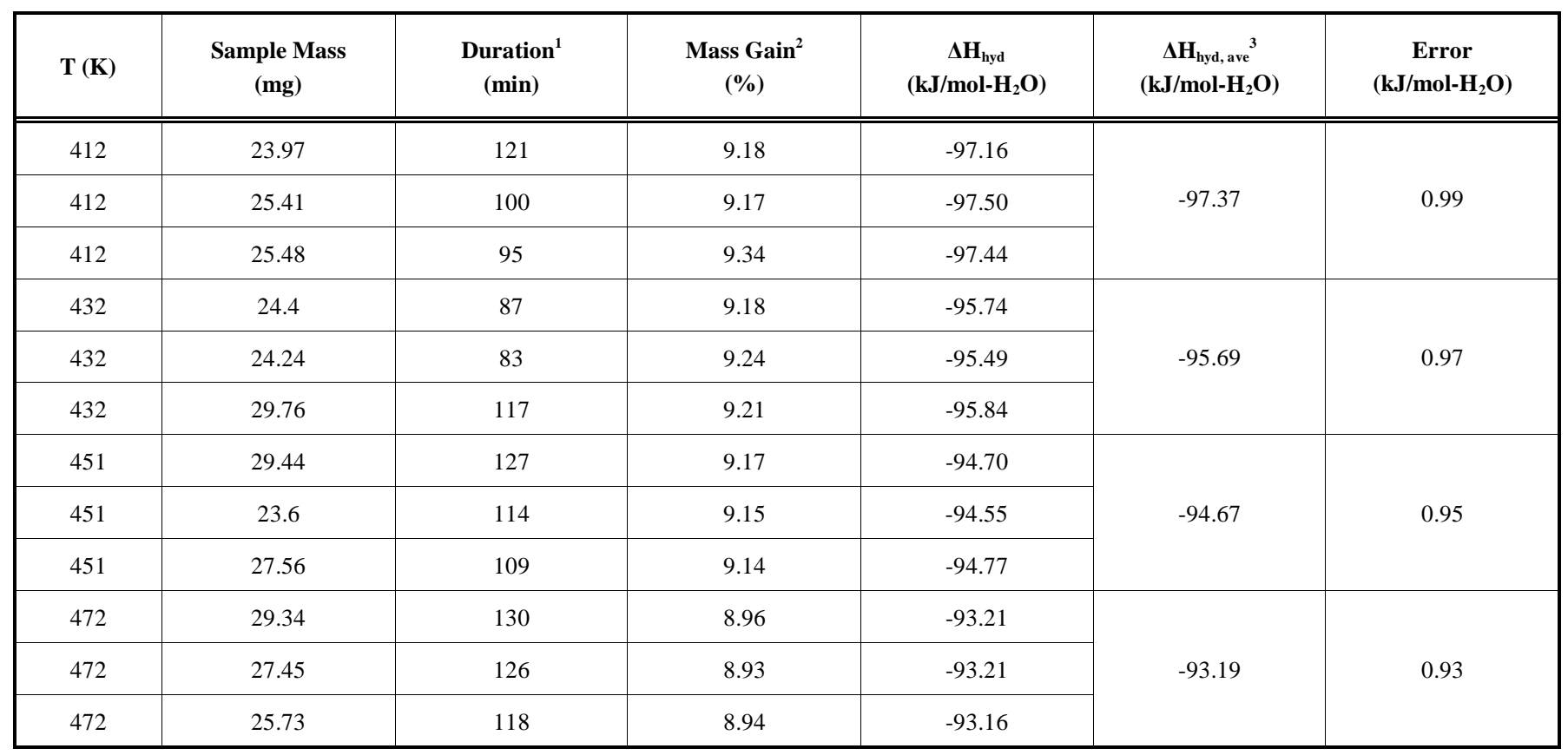

${ }^{1}$ Duration of immersion portion of experiment used in data regression.

${ }^{2}$ Mass of the $\mathrm{H}_{2} \mathrm{O}$ (in percentage) absorbed in that period.

${ }^{3}$ The average value of $\Delta \mathrm{H}_{\text {hyd }}$, as the integral enthalpy of hydration in natrolite.

errors include contributions from both the data variance at a given temperature and the error in the calorimetric calibration $(\sim 1.5 \%)$. The data indicate that $\Delta \mathrm{H}_{\text {hyd }}$ becomes significantly less energetic with increasing temperature, increasing from $\sim-97.4 \mathrm{~kJ} / \mathrm{mol}\left(\mathrm{H}_{2} \mathrm{O}\right)$ at $412 \mathrm{~K}$ to $\sim-93.2 \mathrm{~kJ} / \mathrm{mol}\left(\mathrm{H}_{2} \mathrm{O}\right)$ at $472 \mathrm{~K}$.

The results shown in Table $\mathbf{1}$ and Fig. (5) are generally consistent with those reported previous in the literature (Table 2). Our determination of $\Delta \mathrm{H}_{\text {hyd }}$ at $451 \mathrm{~K}$ in Table $\mathbf{1}$ is less energetic than, but within error of, the previous determination by immersion calorimetry at a similar temperature [25]. The other values of $\Delta \mathrm{H}_{\text {hyd }}$ for natrolite reported in the literature were determined at significantly different temperatures; however, all of the data are similar in magnitude to (and mostly within error of) the results from this study. Of particular note is the value determined at $298.15 \mathrm{~K}$ by [24] using transposed temperature drop calorimetry, which appears to lie along trend with the data generated in this study if reported errors are taken into account.

The temperature dependence of the data shown in Fig. (5) corresponds to the heat capacity of hydration $\left(\Delta \mathrm{C}_{\mathrm{p}, \mathrm{hyd}}\right)$ via the relation

$$
\left(\frac{\partial \Delta \mathrm{H}_{\text {hyd }}}{\partial \mathrm{T}}\right)=\Delta \mathrm{C}_{\mathrm{p}, \mathrm{hyd}} \text {. }
$$

The linear regression shown in Fig. (5) thus corresponds to the average value of $\Delta \mathrm{C}_{\mathrm{p} \text {,hyd }}$ over the temperature interval of the $\Delta \mathrm{H}_{\text {hyd }}$ data (note that previously reported values were not included in the regression). It can be seen from Fig. (5) that the results of this regression calculation are consistent with $\Delta \mathrm{H}_{\text {hyd }}$ reported by [24] at $298.15 \mathrm{~K}$. The value of $\Delta \mathrm{C}_{\mathrm{p} \text {,hyd }}$ determined from this regression, $68.0 \pm 7.8 \mathrm{~J} / \mathrm{mol}\left(\mathrm{H}_{2} \mathrm{O}\right) \mathrm{K}$, is anomalously large relative to previously determined values

Table 2. Enthalpy of Hydration in Natrolite

\begin{tabular}{|c|c|c|c|}
\hline$(\mathrm{NaAl})_{2} \mathrm{Si}_{2} \mathrm{O}_{10} \cdot 2 \mathrm{H}_{2} \mathrm{O}$ & PE, [10] & 900 & -108 \\
\hline Not reported & $\mathrm{PE},[12]$ & 684.15 & $-102.9 \pm 4.0$ \\
\hline$(\mathrm{NaAl})_{2} \mathrm{Si}_{2} \mathrm{O}_{10} \cdot 2 \mathrm{H}_{2} \mathrm{O}$ & IM, [25] & 453.15 & $-100.0 \pm 5.0$ \\
\hline
\end{tabular}

${ }^{1}$ Methods: TTD: transposed temperature drop calorimetry; PE: retrieval from phase equilibrium observations; DSC: calculated from scanning DSC measurement; IM: heat of immersion in water. 
for natrolite or other zeolites. The same sample used in this study was used to determine $\Delta \mathrm{C}_{\mathrm{p} \text {,hyd }}$ previously by $\mathrm{DSC}$ measurement of the heat capacities $\left(\mathrm{C}_{\mathrm{p}}\right)$ of homologous hydrated and dehydrated natrolite [26]. At the lower end of the data shown in Fig. (5), $\Delta \mathrm{C}_{\mathrm{p} \text {,hyd }}$ was found by [26] to be $\sim 17$ $\mathrm{kJ} / \mathrm{mol}\left(\mathrm{H}_{2} \mathrm{O}\right)$. Partial dehydration of the sample precluded determination of $\mathrm{C}_{\mathrm{p}}$ of hydrated natrolite above $\sim 403 \mathrm{~K}$ by [26]. However, using $C_{p}$ data generated by [27] for natrolite and those of [26] for dehydrated natrolite indicate that $\Delta \mathrm{C}_{\mathrm{p} \text {,hyd }}$ at $472 \mathrm{~K}$ (the highest temperature datapoint in Fig. (5)) is essentially the same as that found at $403 \mathrm{~K}$. Thus, $\Delta \mathrm{C}_{\mathrm{p} \text {,hyd }}$ determined by direct determination of $\mathrm{C}_{\mathrm{p}}$ for hydrated and dehydrated natrolite is lower than suggested by the regression in Fig. (5) by a factor of $\sim 4$. Another indication of the anomalous value of $\Delta \mathrm{C}_{\mathrm{p} \text {,hyd }}$ given by the regression in Fig. (5) is the fact that in other zeolites, $\Delta \mathrm{C}_{\mathrm{p} \text {,hyd }}$ rarely exceeds $\sim 25 \mathrm{~J} / \mathrm{mol}\left(\mathrm{H}_{2} \mathrm{O}\right) \mathrm{K}[26,28]$. This is consistent with statistical mechanical models of the heat capacities of confined water molecules in zeolites, which suggest that $\Delta \mathrm{C}_{\mathrm{p} \text {,hyd }}$ should not exceed $3 R$ (where $R$ is the gas constant) [28, 29]. Thus, the temperature dependence of the data in Fig. (5) is clearly anomalous relative to $\Delta \mathrm{C}_{\mathrm{p}, \mathrm{hyd}}$.

There are several potential explanations for the anomalous temperature dependence of the $\Delta \mathrm{H}_{\text {hyd }}$ data in Fig. (5). One potential explanation is that this disparity is related to the decrease in hydration capacity with temperature noted above, with differences in the energetics of the unoccupied water sites from those filled during the experiments. If this were true, however, $\Delta \mathrm{H}_{\text {hyd }}$ for the sites filled last would most likely be less exothermic than the first ones to fill, as observed in other zeolites [16, 23]. Furthermore, there is no indication of changes in $\Delta \mathrm{H}_{\text {hyd }}$ as a function of hydration state in any of the results from the present study. A more likely explanation, which is consistent with the thermodynamic behavior discussed below, is that $\mathrm{C}_{\mathrm{p}}$ is not a linear function of hydration state in the hydrated-dehydrated natrolite solid solution (in which case the disparity between the $\mathrm{C}_{\mathrm{p}}$ and $\Delta \mathrm{H}_{\text {hyd }}$ data would not exist), but rather that excess heat capacity of mixing $\left(C_{p}{ }^{E X}\right)$ is present in this solid solution. In this case, the difference between $\Delta C_{p, h y d}$ determined by regression of the data in Fig. (5) and that assessed from $\mathrm{C}_{\mathrm{p}}$ for hydrated and dehydrated natrolite $\left[\sim 50 \mathrm{~J} / \mathrm{mol}\left(\mathrm{H}_{2} \mathrm{O}\right) \mathrm{K}\right]$ corresponds to the integral of $\mathrm{C}_{\mathrm{p}}$ EX over $\mathrm{X}_{\text {hydrated natrolite }}$

\section{DISCUSSION: NATURE OF THE HYDRATED NA- TROLITE-DEHYDRATED NATROLITE SOLID SO- LUTION}

The hydration and dehydration behavior of natrolite is anomalous relative to that observed in other zeolites. Most zeolites exhibit fully reversible hydration/dehydration in which similar water contents are achieved under identical conditions of temperature, pressure, and the chemical potential of $\mathrm{H}_{2} \mathrm{O}$ during both hydration and dehydration [e.g., 15, $16,30]$ if sufficient time is afforded for equilibration. In dynamic TGA experiments, such as that shown in Fig. (1), water loss from these zeolites occurs gradually over a protracted range of temperature [e.g., 13], particularly at both the low and high temperature portions of the reaction. Additionally, in isothermal hydration experiments, the rate of hydration typically decays exponentially after the reaction beings [e.g., $15,16,23]$. Natrolite, however, exhibits very different behaviors in these types of experiments, particularly at low degrees of hydration. First, there is considerable hysteresis between water contents achieved during hydration and dehydration under the same conditions. For instance, water contents achieved during cooling of natrolite at constant $\mathrm{P}_{\mathrm{H}_{2} \mathrm{O}}$ are considerably lower than those obtained during heating [13]. It is important to note that this hysteresis is not a kinetic effect, as it is repeatable and time-independent, and that it is most pronounced at low degrees of hydration [13]. Second, during dynamic TGA experiments the dehydration reaction proceeds at first gradually, as in other zeolites, and then goes to completion abruptly without a gradual mass loss at the end (high temperature portion) of the reaction (Fig. 1). Lastly, at relatively low degree of hydration, natrolite exhibits an unusual near zero-order rate of hydration (Figs. 2, 3, and 4). Thus there appear to be two distinct phenomena observed in the hydration and dehydration of natrolite: 1) at high degrees of hydration, natrolite exhibits behavior similar to reversible hydration observed in other zeolites; and 2) at relatively low degrees of hydration, natrolite exhibits an abrupt, stepwise hydration/dehydration behavior more akin to that found in hydrate minerals.

The best explanation for the hydration/dehydration behaviors observed in natrolite is that the solid solution between hydrated and dehydrated natrolite is characterized by an asymmetrical solvus that leads to immiscibility between dehydrated natrolite and natrolite exhibiting relatively high degrees of hydration. The abrupt/zero-order hydration/dehydration behavior noted at relatively low degrees of hydration is readily explained if continuous, reversible hydration is not possible due to immiscibility, leading to a step function change in hydration state as a function of time or intensive variables (e.g., temperature in Fig. (1)). It appears that the compositional extent of the solvus decreases with increasing temperature, as shown by the decreasing extent of the zero-order region in Fig. (4). At relatively low temperatures (e.g., Fig. 2) nearly complete immiscibility is present between hydrated and dehydrated natrolite, but with increasing temperature complete solution is possible between hydrated natrolite and an expanding range of hydration states.

If such a solvus exists, this may explain the anomalous temperature dependence of $\Delta \mathrm{H}_{\text {hyd }}$ found in this study. Although not a necessary condition for the presence of a solvus, the presence of $\mathrm{C}_{\mathrm{p}}{ }^{\mathrm{EX}}$ is a common condition in immiscible systems. An alternative explanation is that the excess enthalpy of mixing, $\mathrm{H}^{\mathrm{EX}}$, that gives rise to this solvus is contributing to the heat effects measured in our experiment. If this were true, the effect would arise from differential partial molar enthalpies of hydration between the miscible and immiscible portions of the solution. This behavior is not consistent with our observations which indicate that $\Delta \mathrm{H}_{\text {hyd }}$ does not vary across the solution. Unfortunately, the partially hydrated members of this solution are not quenchable, precluding independent assessment of the magnitude of $\mathrm{H}^{\mathrm{EX}}$ as a function of composition.

The solvus behavior noted above is probably present in a number of other confined water systems involving mineral hydrates. This is probably best established in the case of mesoporous materials, which exhibit hysteretic hydration/dehydration behavior similar to that found in natrolite that is now interpreted in terms of solvus behavior [e.g., 31]. Hysteretic behavior is also noted in the stepwise hydration of 
smectite clay and in the hyperhydration reaction leading to fully-hydrated laumontite [32, 33]. In both of the latter cases, $\mathrm{X}$-ray diffraction observations suggest that the compositional region exhibiting hysteretic behavior is characterized by the presence of two phases, as one would expect from the immiscibility proposed in the present work. The abrupt cessation of reaction noted in the dynamic TGA data for natrolite also appears to be typical of these solvus systems, as we have found both mesoporous materials and dehydration of the hyperhydrate form of laumontite to exhibit this behavior.

\section{ACKNOWLEDGEMENTS}

This work was supported in part by the U.S. National Science Foundation (grant EAR-0336906) to PSN. Discussions and laboratory assistance from L. Ruhl and G. Atalan are greatly appreciated. Constructive reviews by two anonymous reviewers improved the presentation of ideas in this paper.

\section{REFERENCES}

[1] Gottardi, G.; Galli, E. Natural Zeolites. Springer-Verlag: Berlin, 1985; p. 409.

[2] Pauling, L. The structure of some sodium and calcium aluminosilicates. Proc. Natl. Acad. Sci USA, 1930, 16, 453.

[3] Peacor, DR. High-temperature, single-crystal X-ray study of natrolite. Am. Mineral., 1973, 58, 676-680.

[4] Artioli, G.; Smith, J.V.; Kvick, A. Neutron diffraction study of natrolite, $\mathrm{Na}_{2} \mathrm{Al}_{2} \mathrm{Si}_{3} \mathrm{O}_{10} \cdot 2 \mathrm{H}_{2} \mathrm{O}$, at $20 \mathrm{~K}$. Acta Crystallogr. C. Crystal Structure Communications, 1984, 40, 1658-1662.

[5] Joswig, W.; Baur, W.H. The extreme collapse of a framework of NAT topology: The crystal structure of metanatrolite (dehydrated natrolite) at 548 K. Neues jahrbuch fur Mineralogie-Monatshefte, 1995, 1, 26-38.

[6] Alberti, A.; Cruciani, G.; Daura, I. Order-disorder in natrolitegroup minerals. Eur. J. Mineral., 1995, 7, 501-508.

[7] Neuhoff, P.S.; Kroeker, S.; Du, L., Fridriksson, T.H.; Stebbins, J. Order/disorder in natrolite group zeolites: $\mathrm{A}{ }^{29} \mathrm{Si}$ and ${ }^{27} \mathrm{Al}$ MAS NMR study. Am. Mineral., 2002, 87, 1307-1320.

[8] Meier, W.M. The crystal structure of natrolite. Z. Kristallogr., 1960, 113, 430-444.

[9] Alberti, A.; Vezzalini, G. How the structure of natrolite is modified through the heating-induced dehydration. Neues jahrbuch fur Mineralogie. Monatshefte, 1983, 3, 135-144.

[10] Hey, M.H. Studies on the zeolites. Part III. Natrolite and metanatrolite. Mineral. Mag., 1932, 23, 243-289.

[11] Baur, W.H.; Joswig, W. The phases of natrolite occurring during dehydration and rehydration studied by single crystal X-ray diffraction methods between room temperature and $923 \mathrm{~K}$. Neues Jahrbuch fur Mineralogie Monatshefte, 1996, 4, 171-187.

[12] van Reeuwijk, L.P. High-temperature phases of zeolites of the natrolite group. Am. Mineral., 1972, 57, 499-510.

[13] van Reeuwijk, L.P. The Thermal Dehydration of Natural Zeolites. Dissertation. Wageningen, Netherlands, 1974, p. 88.

[14] Bish, D.L.; Carey, J.W. Thermal behavior of natural zeolites. In D.L. Bish and D.W. Ming Eds., Natural Zeolites: Occurrence, Properties, Applications, Rev. Minera. Geochem., Mineralogical
Society of America and the Geochemical Society, Washington, D.C. 2001, pp. 403-452.

[15] Carey, J.W.; Bish, D.L. Equilibrium in the clinoptilolite-H2O system. Am. Mineral., 1996, 81, 952-962.

[16] Fialips, C.I.; Carey, W.J.; Bish, D.L. Hydration-dehydration behavior and thermodynamics of chabazite. Geochim Cosmochim Acta 2005, 69, 2293-2308.

[17] Cammenga, H.K.; Eysel, W.; Gmelin, E.; Hemminger, W.; Höhne, G.W.H.; Sarge, S.M. The temperature calibration of scanning calorimeters. 2. Calibration Substances. Thermochim. Acta, 1993, 219, 333-342.

[18] Gmelin, E.; Sarge, S.M. Temperature, heat and heat flow rate calibration of differential scanning calorimeters. Thermochim. Acta, 2000, 347, 9-13.

[19] Höhne, G.W.H.; Cammenga, H.K.; Eysel, W.; Gmelin, E.; Hemminger, W. The Temperature Calibration of Scanning Calorimeters. Thermochim. Acta, 1990, 160, 1-12.

[20] Sabbah, R.; An, X.W.; Chickos, J.S.; Leitao, M.L.P.; Roux, M.V.; Torres, L.A. Reference materials for calorimetry and differential thermal analysis. Thermochim. Acta, 1999, 331, 93-204.

[21] Sarge, S.M.; Gmelin, E.; Hohne, G.W.H.; Cammenga, H.K.; Hemminger, W.; Eysel, W. The Caloric Calibration of Scanning Calorimeters. Thermochim. Acta, 1994, 247, 129-168.

[22] Stolen, S.; Glockner, R.; Gronvold, F. Heat capacity of the reference material synthetic sapphire (alpha- $\left.\mathrm{Al}_{2} \mathrm{O}_{3}\right)$ at temperatures from $298.15 \mathrm{~K}$ to $1000 \mathrm{~K}$ by adiabatic calorimetry. Increased accuracy and precision through improved instrumentation and computer control. J. Chem. Thermodyn., 1996, 28, 1263-1281.

[23] Neuhoff, P.S. Wang, J. Isothermal measurement of heats of hydration in zeolites by simultaneous thermogravimetry and differential scanning calorimetry. Clays Clay Mineral., 2007, 55, 239-252.

[24] Drebushchak, V.A. Calorimetric studies on dehydrated zeolites: Natrolite, heulandite, chabazite, and mordenite. Geochem. Int., 1990, $5,123-130$.

[24] Kiseleva, I.A.; Ogorodova, L.P.; Melchakova, L.V.; Belitsky, I.A.; Fursenko, B.A. Thermochemical investigation of natural fibrous zeolites. Eur. J. Mineral., 1997, 9, 327-332.

[25] Guliev, T.M.; Isirikyan, A.A.; Mirzai, D.I.; Serpinskii, V.V. Energy of rehydration of natrolite and scolecite. Bull. Acad. Sci. USSR. Div. Chem. Sci., 1989, 37, 1308-1310.

[26] Neuhoff, P.S.; Wang, J. Heat capacity of hydration in zeolites. Am. Mineral., 2007, 92, 1358-1367.

[27] Johnson, G.K.; Flotow, H.E.; O'Hare, P.A.G.; Wise, W.S. Thermodynamic studies of zeolites: Natrolite, mesolite, and scolecite. Am. Mineral., 1983; 68, 1134-1145.

[28] Carey, J.W. The heat capacity of hydrous cordierite above $295 \mathrm{~K}$ Phys. Chem. Miner., 1993, 19, 578-583.

[29] Barrer, R.M. Zeolites and clay minerals as sorbents and molecular sieves. Academic Press, London. 1978, p. 497.

[30] Balgord, W.D.; Roy, R. Crystal chemical relationships in the analcite family. II. Influence of temperature and $\mathrm{P}_{\mathrm{H} 2 \mathrm{O}}$ on structure. Mol. Sieves, 1973, 16, 189-199.

[31] Neimark, A.V.; Ravikovitch, P.I.; Vishnyakov, A. Adsorption hysteresis in nanopores. Phys. Rev. E. Star Phys. Plasmas Fluids Relat., 2000, 62, R1493-R1496.

[32] Fridriksson, T.H.; Carey, J.W.; Bish, D.L.; Neuhoff, P.S.; Bird, D.K. Hydrogen-bonded water in laumontite II: Experimental determination of site-specific thermodynamic properties of hydration of the W1 and W5 sites. Am. Mineral., 2003, 7, 1060-1072.

[33] Tamura, K.; Yamada, H.; Nakazawa, H. Stepwise hydration of high-quality synthetic smectite with various cations. Clays Clay Miner., 2000; 48, 400-404. 